\title{
Effects of laser shock processing, solid solution and aging, and cryogenic treatments on microstructure and thermal fatigue performance of $\mathrm{ZCuAl}_{10} \mathrm{Fe}_{3} \mathrm{Mn}_{2}$ alloy
}

\author{
*Guang-lei Liu" ${ }^{1,2}$, Yu-hao Cao', Lu-xin Shi', Meng-jie Zhang', Zhi-qiang Ye', Ling Zhao', Jian-zhong Zhou', \\ Nai-chao Si ${ }^{1}$ \\ 1. School of Materials Science and Engineering, Jiangsu University, Zhenjiang 212013, China \\ 2. School of Mechanical Engineering, Jiangsu University, Zhenjiang 212013, China
}

\begin{abstract}
The materials used in variable temperature conditions are required to have excellent thermal fatigue performance. The effects of laser shock processing (LSP), solid solution and aging treatment (T6), and cryogenic treatment (CT) on both microstructure and thermal fatigue performance of $Z \mathrm{ZuAl}{ }_{10} \mathrm{Fe}_{3} \mathrm{Mn}_{2}$ alloys were studied. Microstructure and crack morphology were then examined by scanning electron microscopy (SEM) and energy-dispersive X-ray spectroscopy (EDS). The result showed that, after being subjected to the combination treatment of T6+CT+LSP, the optimal mechanical properties and thermal fatigue performance were obtained for the $\mathrm{ZCuAl}_{10} \mathrm{Fe}_{3} \mathrm{Mn}_{2}$ alloy with the tensile strength, hardness, and elongation of $720 \mathrm{MPa}, 300.16 \mathrm{HB}$, and $16 \%$, respectively, and the thermal fatigue life could reach 7,100 cycles when the crack length was $0.1 \mathrm{~mm}$. Moreover, the $\mathrm{ZCuAl}_{10} \mathrm{Fe}_{3} \mathrm{Mn}_{2}$ after combination treatment shows high resistance to oxidation, good adhesion between the matrix and grain boundaries, and dramatically reduced growth rate of crack. During thermal fatigue testing, under the combined action of thermal and alternating stresses, the microstructure around the sample notch oxidized and became loose and porous, which then converted to micro-cracks. Fatigue crack expanded along the grain boundary in the early stage. In the later stage, under the cyclic stress accumulation, the oxidized microstructure separated from the matrix, and the fatigue crack expanded in both intergranular and transgranular ways. The main crack was thick, and the path was meandering.
\end{abstract}

Key words: $\mathrm{ZCuAl}_{10} \mathrm{Fe}_{3} \mathrm{Mn}_{2}$ alloy; laser shock processing; $\mathrm{T} 6$ treatment; cryogenic treatment; microstructure; thermal fatigue; crack initiation and propagation

CLC numbers: TG146.1 1 Document code: A Article ID: 1672-6421(2021)02-155-08

\section{Introduction}

Copper alloys have excellent mechanical properties, high electrical and thermal conductivity, good resistance to wear and corrosion, and a high recycling rate. Certain parts made from copper alloys are extensively used in automobile, aircraft, and ship-building industries. But, their thermal fatigue performance needs to be improved for extending the application fields of the copper alloys to extreme conditions such as high temperature or

\section{*Guang-lei Liu}

Male, Ph. D, Associate Professor. His research interests mainly focus on metal casting, toughening and strengthening, as well as surface laser processing of metals.

E-mail: liugl@ujs.edu.cn;

Received: 2020-09-30; Accepted: 2021-01-18 variable temperature condition. The improvement of thermal fatigue performance by conventional solution and aging heat treatment (T6) is insufficient to meet the increasing demands of industrial development ${ }^{[1-3]}$.

Some new methods have been developed to improve the performance of copper alloys under extreme conditions. Laser shock processing (LSP) is a highly efficient surface treatment technique which uses shockwaves to produce high-amplitude residual compressive stress on the material surface. Compared with conventional machining, LSP can generate an effective depth on the metal's surface that is many times larger than that using shock peen, therefore considerably improving its fatigue life. Nevertheless, under high temperature or variable temperature, a considerable amount of LSP-induced residual stress is released, which greatly reduces the strengthening effect. It has 
also been found that the high strain rate plastic deformation formed by LSP shockwave can realize the nanocrystallization of the metal surface and improve the comprehensive properties of materials at high temperature ${ }^{[4-8]}$.

Studies on cryogenic treatment (CT) began in the United States in the $1950 \mathrm{~s}$, and then CT was originally used for improving the mechanical properties of steels ${ }^{[9,10]}$. In the last few years, the strengthening effect of $\mathrm{CT}$ on $\mathrm{Cu}$ alloys has been of wide concern. It has been pointed out that cryogenic treatment is beneficial to induce phase transformation in the $\mathrm{Cu}$ alloy ${ }^{[11]}$. This is similar to the transformation of retained austenite to martensite after the cryogenic treatment of steel. CT can promote the precipitation of the second phase that is dispersed across the matrix and refine the grains ${ }^{[12]}$. Although both LSP and CT can improve the mechanical properties of copper alloys, their effects on thermal fatigue properties are unclear. In particular, a systematic study on the strengthening mechanism of copper alloys using a combined process, including heat treatment (T6), CT and LSP, is still lacking; therefore, additional studies are required ${ }^{[13]}$.

In this study, five states of $\mathrm{ZCuAl}_{10} \mathrm{Fe}_{3} \mathrm{Mn}_{2}$ alloy samples: ascast, T6-treated, CT-treated, LSP-treated, and T6+CT+LSPtreated, were prepared. The influences of different techniques on the microstructure and thermal fatigue performance of alloys were compared and their strengthening mechanisms were analyzed to develop the fundamental theory for expanding the application of copper alloys.

\section{Experimental methods}

Commercial $\mathrm{ZCuAl}_{10} \mathrm{Fe}_{3} \mathrm{Mn}_{2}$ alloy was used, and its chemical composition is listed in Table 1. The sample preparation process of the five states is shown in Table 2. The experimental samples were processed by wire cutting. CT was performed in liquid nitrogen for $2 \mathrm{~h}$ followed by air-cooling, while LSP was performed using a Thales lamp pumped high-energy solid-state laser (GAIA-1064), with a K9 glass overlay (tamping layer) and aluminum foil with a thickness of $0.3 \mathrm{~mm}$ as the ablative layer. The process parameters are shown in Table 2. Figure 1 shows the dimensions of the samples used in the tensile testing and thermal fatigue testing. The thickness of the thermal fatigue sample is $5 \mathrm{~mm}$. The pre-made notch on the sample is to form stress concentration and make cracks preferentially grow on this site. The oblique line areas in Figs. 1(a) and (b) are LSPstrengthening zones. The laser shock processing path is shown in Fig. 1(c).

Thermal fatigue testing was carried out on the LRS1200 thermal fatigue testing machine. Samples for testing were mechanical polished and subsequently observed under an optical microscope (OM), and the samples without defects such as cracks and pores in the notch area were selected for the thermal fatigue testing. The sample was put into the thermal fatigue testing machine and heated at a heating rate of $5{ }^{\circ} \mathrm{C} \cdot \mathrm{min}^{-1}$. When the temperature reached $450{ }^{\circ} \mathrm{C}$, the sample was held for $120 \mathrm{~s}$, then cooled with circulating cooling

Table 1: Chemical composition of $\mathrm{ZCuAl}_{10} \mathrm{Fe}_{3} \mathrm{Mn}_{2}$ alloy (wt.\%)

\begin{tabular}{ccccccccccc} 
Al & Fe & Mn & Zn & Sn & Si & P & Pb & Impurity & Cu \\
\hline 9.89 & 3.06 & 1.78 & 0.46 & $\leq 0.1$ & $\leq 0.1$ & $\leq 0.01$ & $\leq 0.03$ & $\leq 0.75$ & Bal.
\end{tabular}

Table 2: Preparation process of five state samples

Sample number

2

3

4
Sample state

As-cast

CT

T6

LSP
Process

Immerse the sample in liquid nitrogen for $2 \mathrm{~h}$, air-cooling

Solution treatment: $950 \pm 5^{\circ} \mathrm{C}, 1 \mathrm{~h}$, water-cooling

Aging treatment: $350 \pm 5^{\circ} \mathrm{C}, 1 \mathrm{~h}$, water-cooling

Spot diameter: $3 \mathrm{~mm}$

Pulse energy: $4 \mathrm{~J}$

Overlap ratio: $50 \%$

Wavelength: $1,064 \mathrm{~nm}$

Frequency: $1 \mathrm{~Hz}$

5

$\mathrm{T} 6+\mathrm{CT}+\mathrm{LSP}$ 
(a)

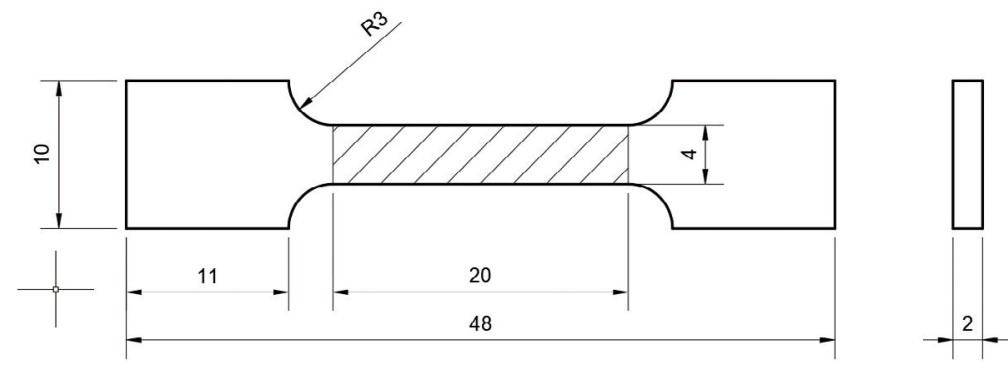

(b)

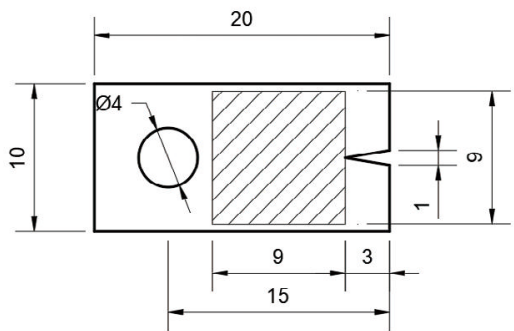

(c)

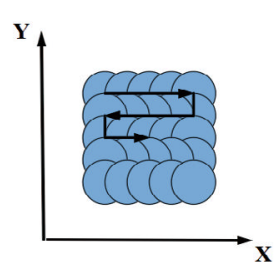

Fig. 1: Schematic diagram of tensile testing sample (a), thermal fatigue testing sample (b), and laser shock processing path (c) (unit: $\mathrm{mm}$ )

water for $10 \mathrm{~s}$, repeating the process for 1,000 cycles. Then, the sample was removed from the testing machine and its microstructure as well as thermal fatigue crack initiation and propagation were examined using a Hitachi S-3400 scanning electron microscope (SEM).

\section{Results and discussion}

\subsection{Microstructure}

Figure 2 shows the microstructure of five samples. Figure 3 shows the energy-dispersive X-ray spectroscopy (EDS) spectra of four phases indicated by the red circle in Fig. 2(a). The ascast sample is primarily composed of the primary $\alpha$ phase, $\beta-\mathrm{Cu}_{3} \mathrm{Al}$ phase, $\left(\alpha+\gamma_{2}\right)-\mathrm{Cu}_{9} \mathrm{Al}_{4}$ eutectoid, and the dispersed tiny, spherical, or quincunx iron-rich $\kappa-A l F e$ phase, as shown in Fig. 2(a) and Fig. 3. For the as-cast sample, the microstructure is dominated by coarse $\alpha$ solid solution which is unevenly distributed. After being subjected to CT, a certain number of $\alpha+\gamma_{2}$ phase and $\kappa$ phase precipitate along the grain boundaries [Fig. 2(b)]. Figure 2(c) shows that most of the second phases such as $\alpha+\gamma_{2}$ phase and $\kappa$ phase are dissolved into in the matrix after T6. Compared to the microstructure of the as-cast sample

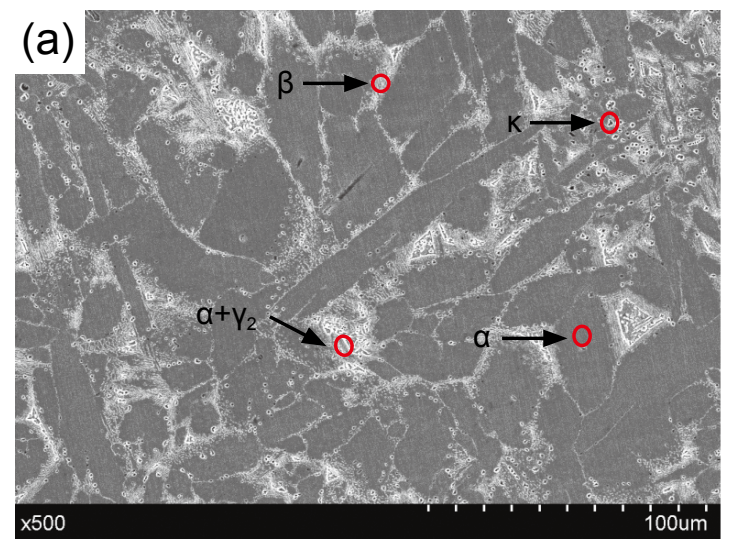

and CT-treated sample, $\alpha$ phase is more regular and the $\beta$ phase increases in number and gathers together in the sample treated by T6. Figure 2(d) shows the sample's surface microstructure after being subjected to LSP, and the inset shows the crosssectional microstructure of the impact zone and matrix. Compared with the matrix, the microstructure of the impact zone is refined significantly, and a large amount of $\kappa$ phase precipitates. Furthermore, there is a clear boundary between the impact zone and the unaffected zone. Figure 2(e) shows the microstructure of the surface after T6+CT+LSP treatment, the inset is an image of the cross-sectional microstructure of the impact zone and matrix. Compared with the LSP-treated sample, there is no obvious boundary between the impact area and the non-impact area. Compared with the as-cast sample, CT-treated sample, T6-treated sample and LSP-treated sample, $\alpha$ phase in the T6+CT+LSP-treated sample is finer and the distribution is more uniform.

\subsection{Mechanical properties}

Figure 4 shows the mechanical properties of five samples. Note that CT, T6, and LSP treatments improve the strength of $\mathrm{ZCuAl}_{10} \mathrm{Fe}_{3} \mathrm{Mn}_{2}$ alloy. According to the above microstructure analysis, the microstructure is mainly $\alpha$ and $\beta$ phases after

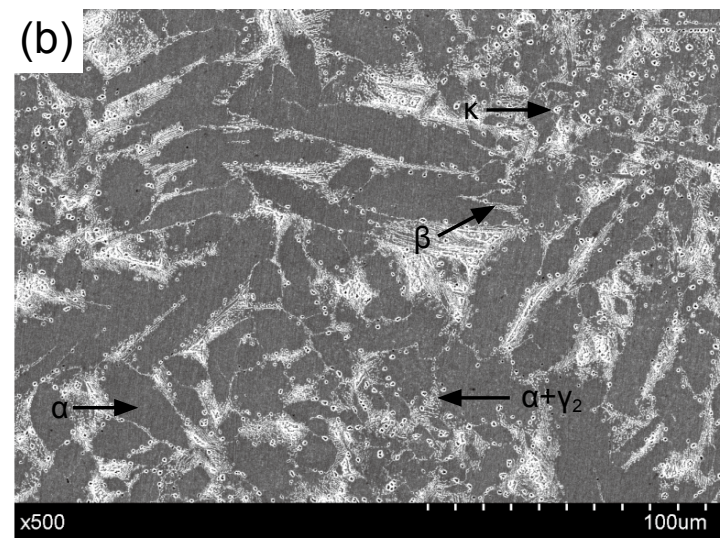



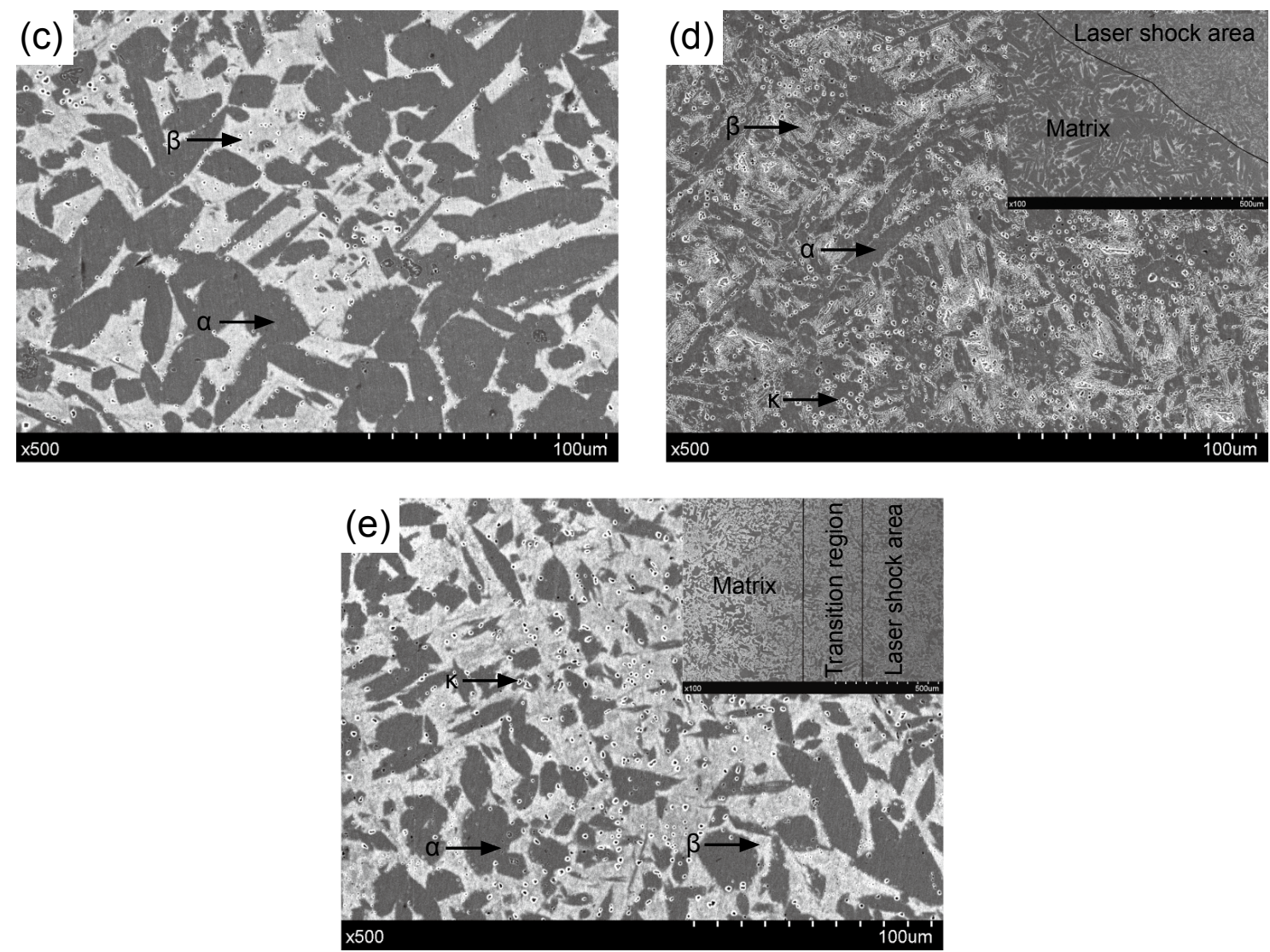

Fig. 2: Microstructure of ZCuAl10Fe $\mathrm{Mn}_{2}$ alloy: (a) as-cast sample; (b) CT-treated sample; (c) T6-treated sample; (d) LSP-treated sample; (e) T6+CT+LSP-treated sample

(a)

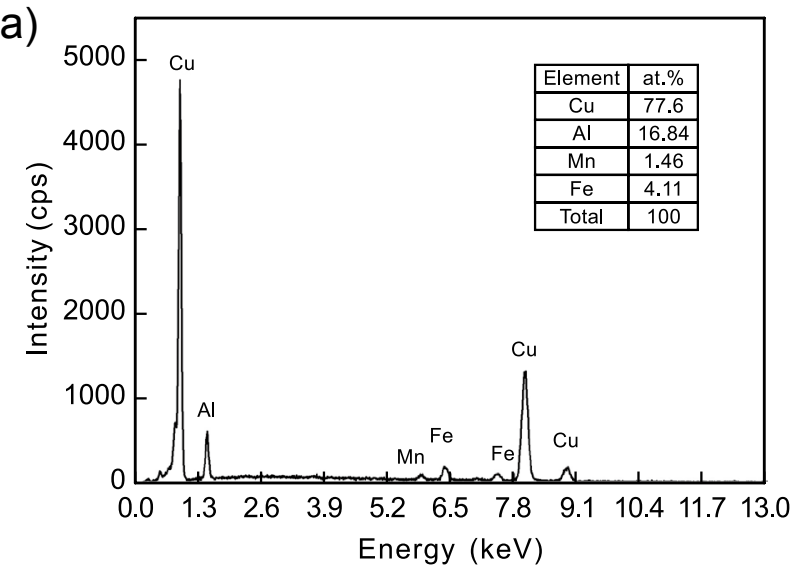

(c)

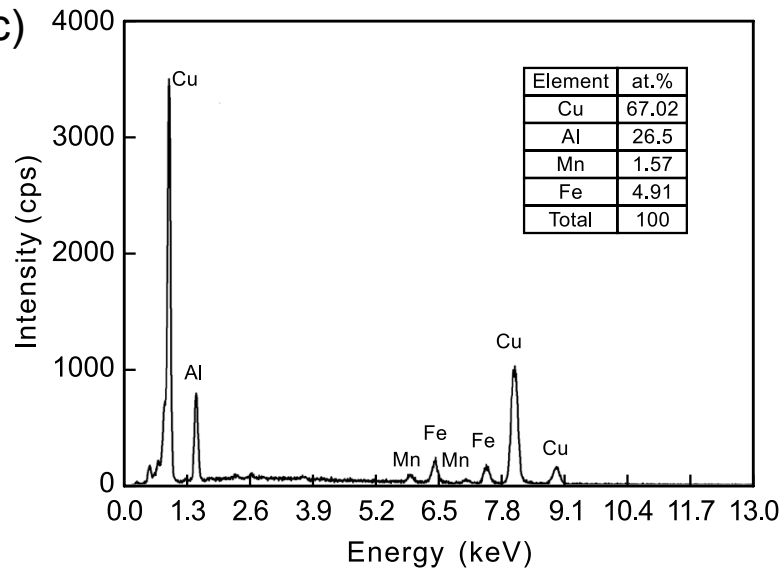

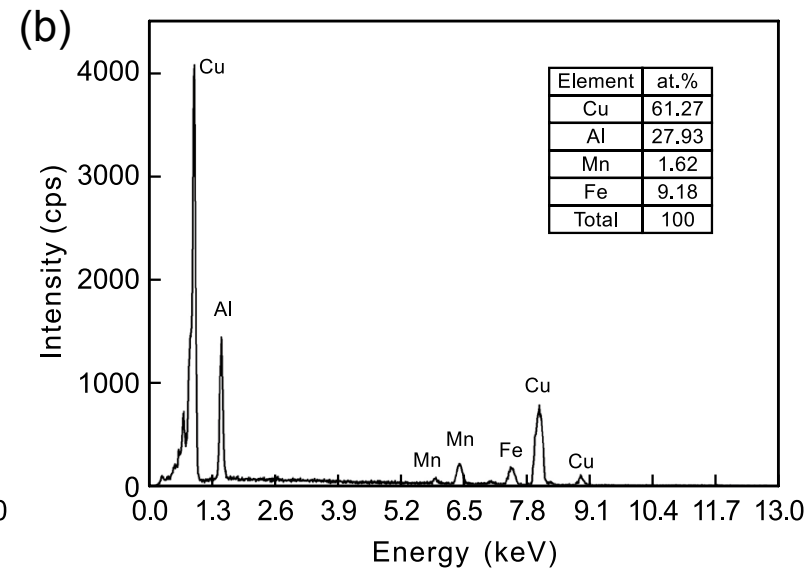

(d)

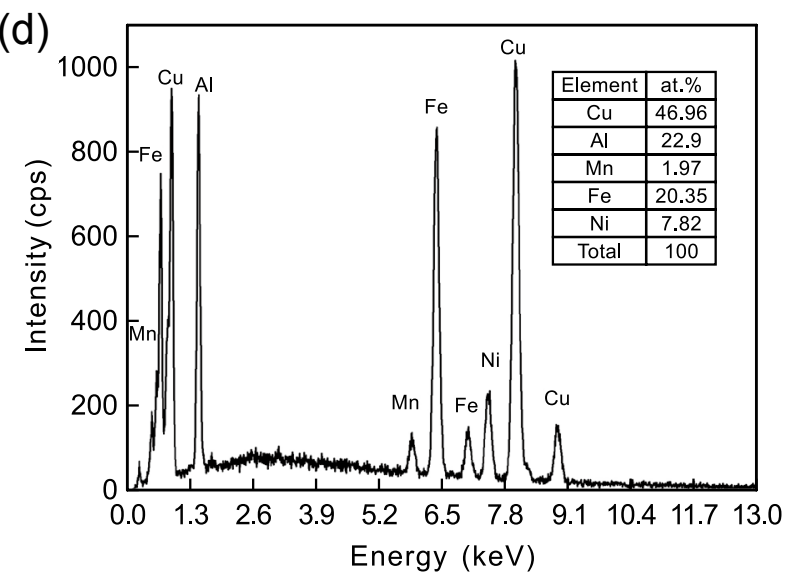

Fig. 3: EDS diagram of as-cast $\mathrm{ZCuAl}_{10} \mathrm{Fe}_{3} \mathrm{Mn}_{2}$ alloy: (a) $\alpha$ phase; (b) $\beta$ phase; (c) $\alpha+\gamma_{2}$ phase; (d) $\mathrm{k}$ phase 
T6 treatment, and the $\kappa$ and $\gamma_{2}$ phases are mainly induced by CT. Both $\kappa$ phase and $\gamma_{2}$ phase are hard and brittle. They can play a role of precipitation strengthening but deteriorate the plasticity of the $\mathrm{ZCuAl}_{10} \mathrm{Fe}_{3} \mathrm{Mn}_{2}$ alloy. LSP can refine the microstructure of the impact area significantly, but the impact area was usually within $1 \mathrm{~mm}$ below the shock surface ${ }^{[14]}$. Under the experimental conditions, the effective thickness of refinement is $0.9 \mathrm{~mm}$. If the thickness of the sample is greater than $2 \mathrm{~mm}$, the effect of LSP on the refinement of microstructure cannot be achieved completely. Therefore, compared with the single process such as LSP or T6, the T6 + CT + LSP process has a better strengthening effect on the $\mathrm{ZCuAl}_{10} \mathrm{Fe}_{3} \mathrm{Mn}_{2}$ alloy components with a thickness greater than $2 \mathrm{~mm}$.

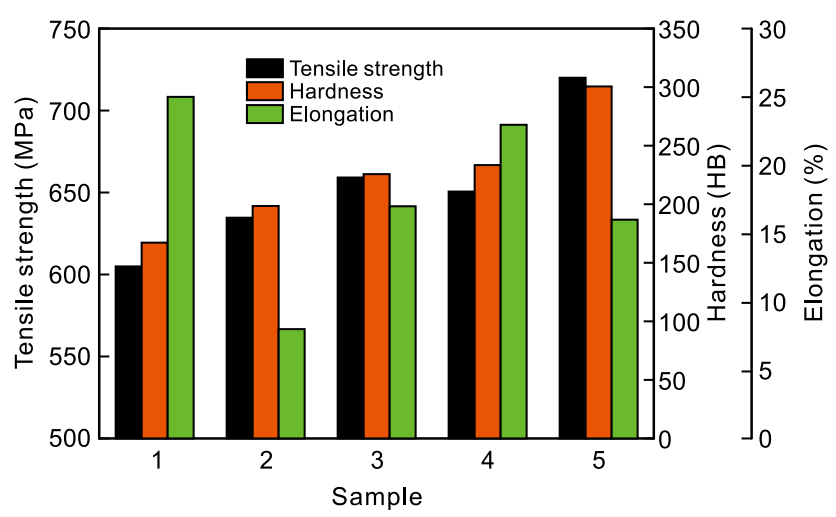

Fig. 4: Mechanical properties of $\mathrm{ZCuAl}_{10} \mathrm{Fe}_{3} \mathrm{Mn}_{2}$ alloy

\subsection{Thermal fatigue property}

Figure 5 shows the thermal fatigue-induced crack growth curves of the five samples. With the increase of cycle number, except for the CT-treated sample, the thermal fatigue crack growth rate of $\mathrm{ZCuAl}_{10} \mathrm{Fe}_{3} \mathrm{Mn}_{2}$ alloy with different treatment processes slowly increases at first, and then it takes on a steeper upward slope and finally decreases. At the early stage (i.e., initiation stage) of the crack growth, the CT-treated sample shows the worst thermal fatigue performance and the samples treated by LSP and T6+CT + LSP display the best thermal fatigue performance. When the number of cycles is 4,000 , there is no crack in the LSP-treated sample and the T6+CT+LSP-treated sample. At the late stage (propagation stage), the worst thermal fatigue performance is obtained by the as-cast sample. The crack length of the LSP-treated sample is shorter, but the crack growth rate is faster which is close to that of as-cast sample. After T6+CT+LSP treatment, the crack initiation and propagation are the slowest, so the thermal fatigue performance is the best.

\subsection{Thermal fatigue crack growth behavior}

Figure 6 shows the microstructures in the vicinity of the notch at the crack initiation stage of thermal fatigue for all five samples. For the as-cast sample [Fig. 6(a)], the oxidation zone is first formed near the notch when subjected to both alternating temperature and stress, which causes the microstructure to become more porous and expedites crack

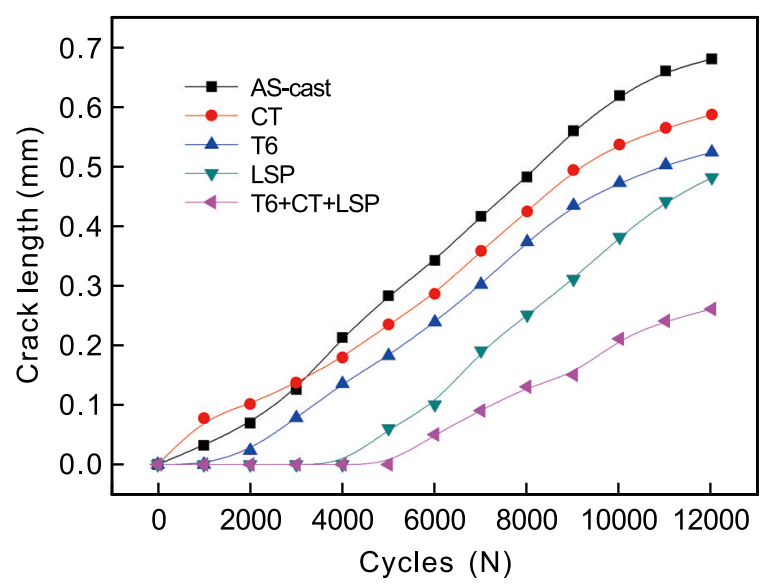

Fig. 5: Thermal fatigue crack growth curves of $\mathrm{ZCuAl}_{10} \mathrm{Fe}_{3} \mathrm{Mn}_{2}$ alloy

growth. The EDS analysis of the oxidation zone [red box in Fig. 6(a)] is shown in Fig. 6(f). For the CT-treated [Fig. 6(b)] and T6-treated [Fig. 6(c)] samples, although they become more resistant to oxidation, a considerable amount of brittle phase precipitates at the grain boundaries. Consequently, the binding strength between the grain boundaries and the matrix weakens, the crack begins to grow along the grain boundary, which leads to the deterioration of plasticity. The microstructure uniformity of the T6-treated sample is better than that of the CT-treated sample, and the thermal fatigue crack growth resistance of the T6-treated sample is better. Therefore, the CT-treated sample has the fastest crack growth rate at the initiation stage when the crack length is less than $0.1 \mathrm{~mm}$ and has poor plasticity. After LSP treatment [Fig. 6(d)], compared with the as-cast sample, the oxidation area at the notch is smaller. Using an X-350A X-ray stress analyzer with the $\chi$ method and a fixed $\psi$, the residual stress at the thermal fatigue specimen surface with notch induced by LSP is $268.5 \mathrm{MPa}$, while tensile stress on the surface of as-cast sample is $32 \mathrm{MPa}$. Residual stress counteracts the externally applied alternating stress and oxidation, which is beneficial to improve the thermal fatigue property. Furthermore, LSP obviously refines the surface microstructure of the sample [Fig. (2)], and makes the microstructure more compact, which therefore improves the thermal fatigue properties of the alloy. After T6+CT+LSP treatment, the microstructure of the sample is highly compact with all constituent phases being refined and homogeneously distributed. Therefore, it improves oxidation resistance and thermal fatigue performance.

With the accumulation of cyclic stress and further proceed of oxidation, the microstructure near the notch of each of the five state samples at the thermal fatigue crack propagation stage is different from that in the initiation stage, as shown in Fig. 7. Although the main crack is usually only one, there are a few microcracks near the notch. The driving force of crack growth would be effectively dispersed, by the appearance of microcracks near the notch, as shown in Fig. 7(a). The above changes are also the reason why the crack growth rate slows down in the thermal fatigue crack propagation stage. 

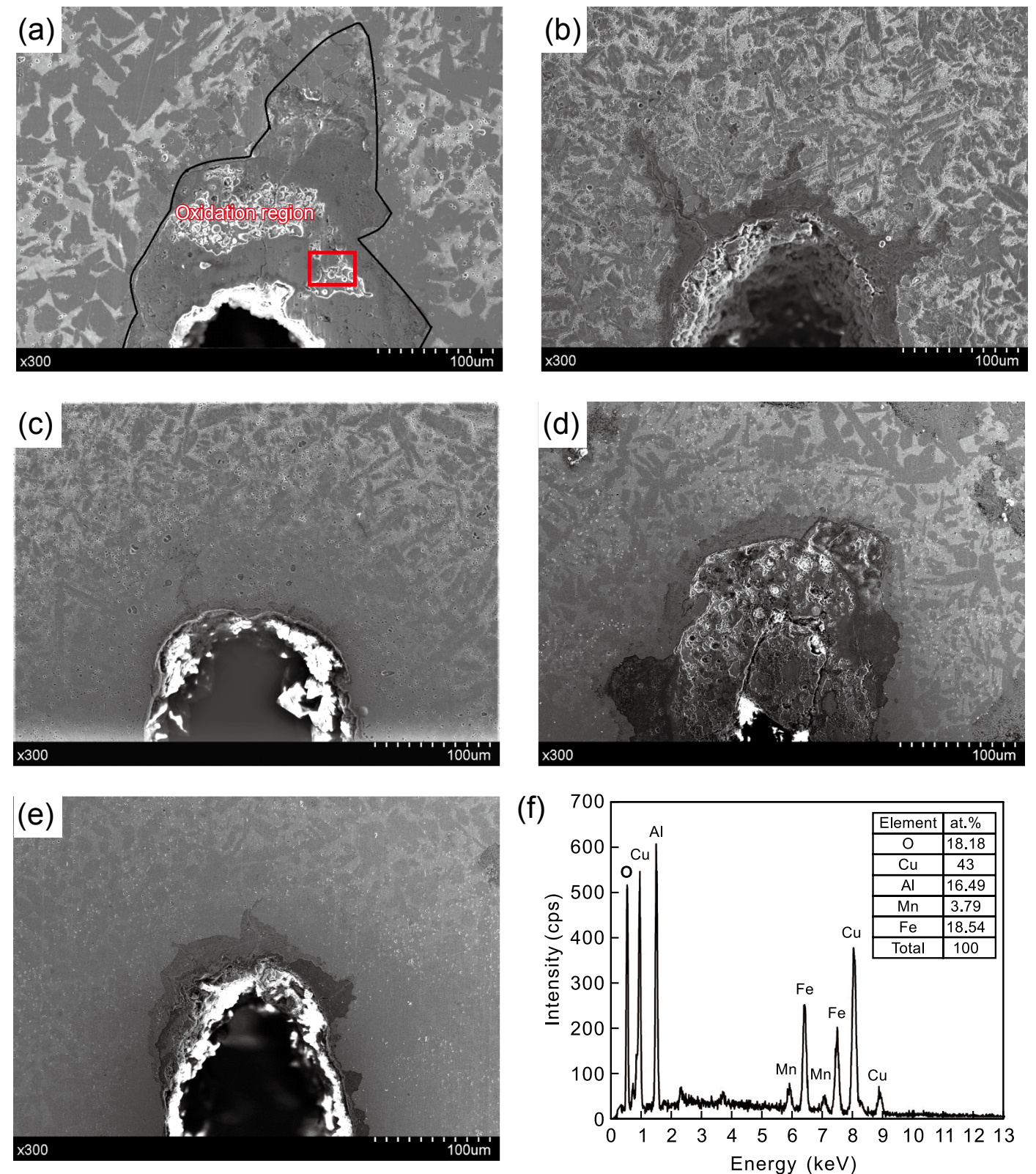

Fig. 6: Microstructures near notch in thermal fatigue crack initiation stage: (a) as-cast sample, 4,000 cycles;

(b) CT-treated sample, 4,000 cycles; (c) T6-treated sample, 4,000 cycles; (d) LSP-treated sample, 6,000 cycles; (e) T6+CT+ LSP-treated sample, 6,000 cycles; (f) EDS of red box area in Fig. 6a

When there are more precipitates in the $\mathrm{ZCuAl}_{10} \mathrm{Fe}_{3} \mathrm{Mn}_{2}$ alloy microstructure, it leads to the phenomenon that the crystalline grain and grain boundary phases separate and drop from the matrix, as shown in Fig. 7(b). This detached phenomenon predominantly occurs at the grain boundaries or defects, and new cracks initiate near the detached regions, causing more second phase to detach. During the process of thermal fatigue, microstructures drop from the matrix preferentially diverting the driving force for crack growth and inhibiting the crack growth ${ }^{[15]}$. Therefore, compared with the as-cast sample, thermal fatigue performance of sample is improved by the CT treatment. For the T6+CT+ LSP-treated sample [Fig. 7(e)], T6 treatment can improve the mechanical properties of the alloy by solution and aging at first, then CT treatment can eliminate the residual stress within the alloy, and LSP treatment can reserve the compressive stress ${ }^{[16,17]}$. In a word, at the thermal fatigue crack propagation stage, the combined process of T6+CT + LSP significantly improves the thermal fatigue performance of $\mathrm{ZCuAl}_{10} \mathrm{Fe}_{3} \mathrm{Mn}_{2}$ alloy.

Thermal fatigue crack growth pattern of as-cast sample with 12,000 cycles is shown in Fig. 8. During the crack initiation stage, the thermal fatigue crack mainly propagates intergranularly, as shown in Fig. 8(1). On the one hand, because of the mismatch in expansion coefficient between the grain boundaries and $\alpha$ phase, the expansion or shrinking of either side causes plastic deformations to build up at the grain boundaries. On the other hand, because grain boundaries have relatively lesser resistance against plastic deformation ${ }^{[18,19]}$, oxygen easily diffuses into the interior of the alloy under thermal stress, resulting in the weakening of grain boundary strength ${ }^{[20]}$. 

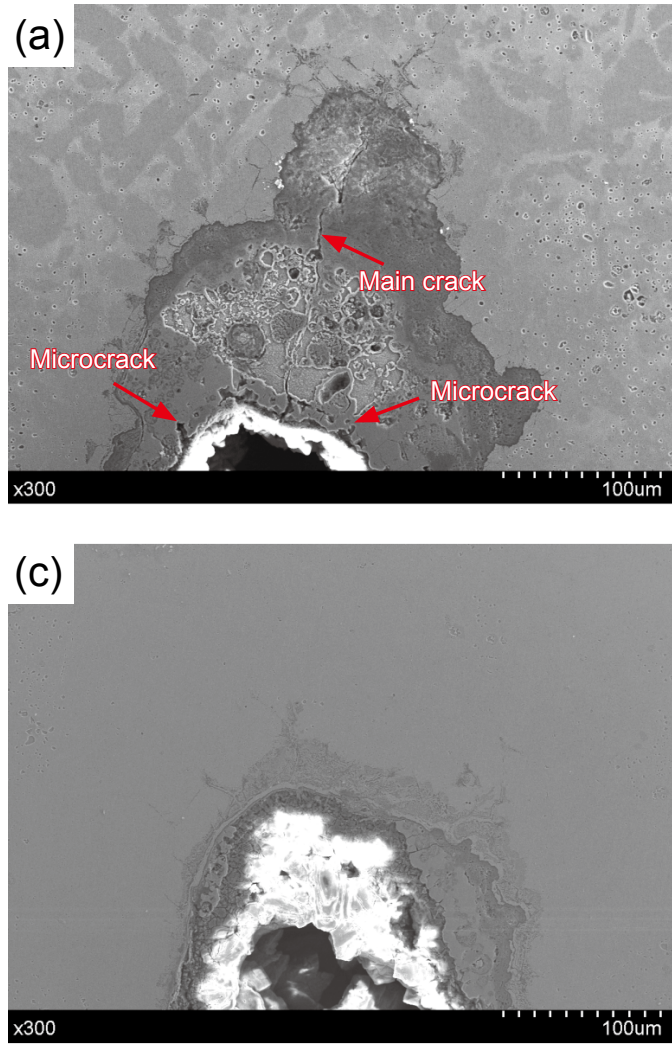

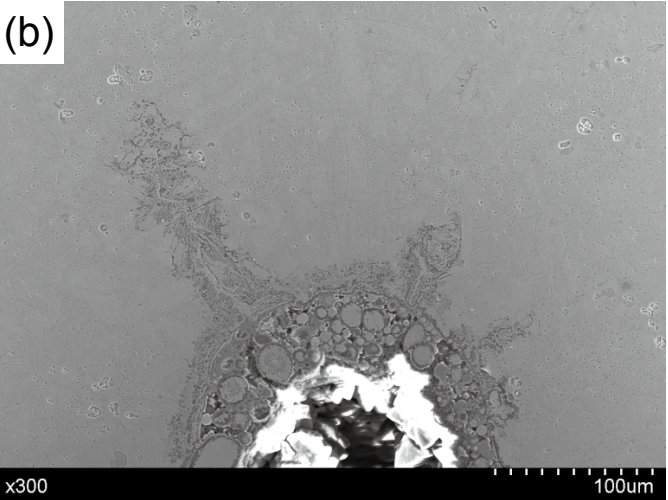

(d)

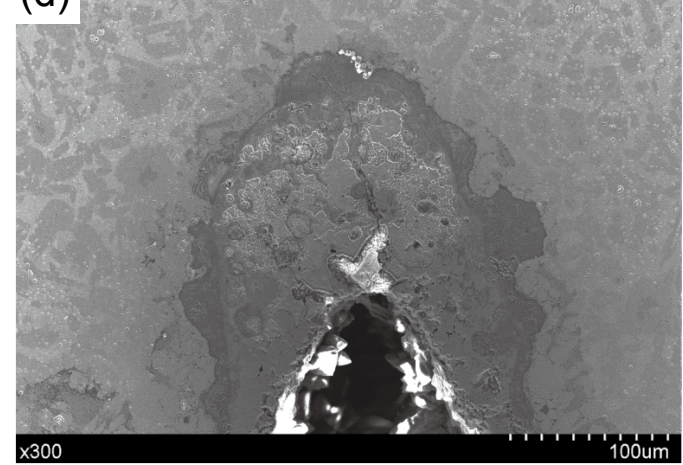

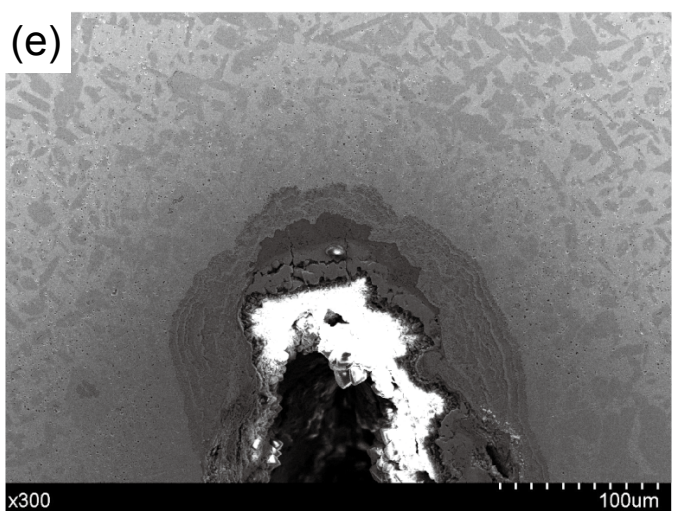

Fig. 7: Microstructures near notch of samples in thermal fatigue crack propagation stage: (a) as-cast sample, 10,000 cycles; (b) CT-treated sample, 10,000 cycles; (c) T6-treated sample, 10,000 cycles; (d) LSP-treated sample, 12,000 cycles; (e) T6+CT+ LSP-treated sample, 12,000 cycles

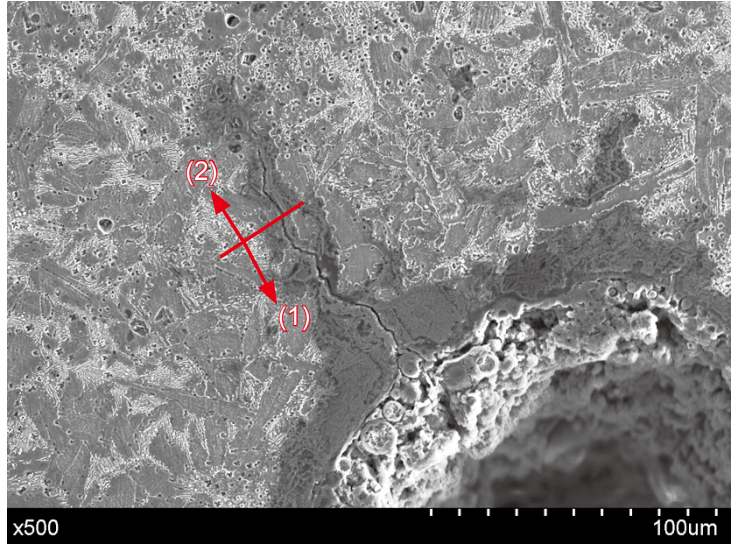

Fig. 8: Thermal fatigue crack growth pattern of as-cast sample with 12,000 cycles
Due to the principle of minimum energy consumption, cracks grow naturally and preferentially at the grain boundaries. Therefore, the $\mathrm{Cu}$ alloy with excellent grain boundary strength and resistance to high temperature oxidation is desirable at the crack initiation stage. During the crack propagation stage, as shown in Fig. 8(2), the cumulative plastic deformation damage exceeds the yield strength of $\mathrm{ZCuAl}_{10} \mathrm{Fe}_{3} \mathrm{Mn}_{2}$ alloy, the crack naturally tends to intergranular and transgranular propagation. In conclusion, the $\mathrm{Cu}$ alloy with good yield strength property is desirable at the crack propagation stage.

\section{Conclusions}

(1) The as-cast $\mathrm{ZCuAl}_{10} \mathrm{Fe}_{3} \mathrm{Mn}_{2}$ alloy is mainly composed of primary $\alpha$ phase, $\beta-\mathrm{Cu}_{3} \mathrm{Al}$ phase, $\left(\alpha+\gamma_{2}\right)-\mathrm{Cu}_{9} \mathrm{Al}_{4}$ phase, and $\kappa-\mathrm{AlFe}$ phase. After $\mathrm{CT}$ treatment, a large number of brittle 
$\gamma_{2}$ and $\kappa$ phases precipitate at the grain boundary. After T6 treatment, $\alpha$ phase is refined with a more regularized shape, the number of brittle $\beta$ phase increases. After LSP treatment, the refinement effect considerably increases with a considerable amount of $\kappa$ phase precipitating out. After T $6+\mathrm{CT}+\mathrm{LSP}$ treatment, the grain size of the alloy is the smallest, the roundness of $\alpha$ phase is the best, and the distribution of grain boundary phase is the most uniform in the matrix.

(2) The combined treatment of T6+CT + LSP can significantly improve the thermal fatigue performance of the $\mathrm{ZCuAl}_{10} \mathrm{Fe}_{3} \mathrm{Mn}_{2}$ alloy. If the component does not require high thermal fatigue performance, LSP is preferred for thin-walled components, and $\mathrm{T} 6$ is considered quite suitable for thick-walled ones.

(3) LSP can refine microstructure and generate preinduced compressive stresses in the alloy and improve the microstructural compactness and oxidation resistance, which is beneficial to the thermal fatigue performance of the alloy.

(4) At the crack initiation stage, thermal fatigue cracks primarily propagate along the grain boundaries. At the late stage of crack growth, the cracks tend to intergranular and transgranular propagation.

\section{Acknowledgements}

Foundation items: National Natural Science Foundation of China (51801076); Natural Science Research of Jiangsu Higher Education Institutions of China (18KJB430009); Jiangsu Province Postdoctoral Science Foundation (1601055C); Senior Talents Research Startup of Jiangsu University (14JDG126).

\section{References}

[1] Wu J H, Zhang S H, Chen Y, et al. Microstructure and properties of TP2 copper tube with La microalloying by horizontal continuous casting. China foundry, 2018, 15(1): 31-36.

[2] Zhao L, Liu G L, Zhang S Y, et al. Effect of compound cryogenic treatment on microstructure and thermal fatigue properties of $\mathrm{ZCuAl}_{10} \mathrm{Fe}_{3} \mathrm{Mn}_{2}$ alloy. Journal of Materials Engineering, 2019, 47(12): 63-70. (In Chinese)

[3] Ma Q, Liu G L, Zhang L Y, et al. Effects of solid solution and aging and cryogenic treatment on friction and wear properties of ZQAI10-3-1.5 alloy. Transactions of Materials and Heat Treatment, 2018, 39(2): 32-37. (In Chinese)

[4] Zhou J Z, Li J, Xu S Q, et al. Improvement in fatigue properties of 2024-T351 aluminum alloy subjected to cryogenic treatment and laser peening. Surface and Coating Technology, 2018, 345: 31-39.

[5] Chen X, Wang Z S, Li Y X, et al. Effects of carbon content on high-temperature mechanical and thermal fatigue properties of high-boron austenitic steels. China Foundry, 2016, 13(1): 1-8.
[6] Cui $C Y$, Wan $T Y$, Shu $Y X$, et al. Microstructure evolution and mechanical properties of aging $6061 \mathrm{Al}$ alloy via laser shock processing. Journal of Alloys and Compounds, 2019, 803: $1112-1118$

[7] Zhou J Z, Li J, Huang S, et al. Influence of cryogenic treatment prior to laser peening on mechanical properties and microstructural characteristics of TC6 titanium alloy. Materials Science and Engineering A, 2018, 718: 207-215.

[8] Cao J D, Zhang J S, Hua Y Q, et al. Low-cycle fatigue behavior of Ni-based superalloy $\mathrm{GH} 586$ with laser shock processing. Journal of Wuhan University of Technology-Materials Science Edition, 2017, 32(5): 1186-1192.

[9] Kara F, Karabatak M, Ayyildiz M, et al. Effect of machinability, microstructure and hardness of deep cryogenic treatment in hard turning of AISI D2 steel with ceramic cutting. Journal of Materials Research and Technology, 2020, 9(1): 969-983.

[10] Lu XY, Wu Z W, He X, et al. Effect of deep cryogenic treatment on martensitic lath refinement and nano-twins formation of low carbon bearing steel. Journal of Iron and Steel Research International, 2020, 27(1): 105-113.

[11] Cai B Z, Ma X L, Moering J, et al. Enhanced mechanical properties in $\mathrm{Cu}-\mathrm{Zn}$ alloys with a gradient structure by surface mechanical attrition treatment at cryogenic temperature. Materials Science and Engineering: A, 2015, 626: 144-149.

[12] Liu K, Chen X Z, Shen Q K, et al. Microstructural evolution and mechanical properties of deep cryogenic treated Cu-Al-Si alloy fabricated by Cold Metal Transfer (CMT) process. Materials Characterization, 2020, 159: 110011.

[13] Zhao L. Effect of cryogenic and laser shock on microstructure and thermal fatigue properties of aluminum bronze alloy. Master dissertation, Zhenjiang: Jiangsu University, 2019. (In Chinese)

[14] Jiang $Y F$, Wang $S L$, Jiang $W F$, et al. Fatigue life and fracture evolution of small-hole specimens by laser shock processing. Optics and Laser Technology, 2020, 131.

[15] Zhang J L, Zhao Z H, Kong $\mathrm{Y} \mathrm{H}$, et al. Crack initiation and propagation mechanisms during thermal fatigue in directionally solidified superalloy DZ125. International Journal of Fatigue, 2019, 119: 355-366.

[16] Zhang L Y, Liu G L, Li Q L, et al. Effect of rapid cryogenic treatment on microstructure and properties of $\mathrm{Al}-10 \mathrm{Si}-5 \mathrm{Cu}$ $0.75 \mathrm{Mg}-0.55 \mathrm{Mn}$ alloy. Transactions of Materials and Heat Treatment, 2018, 39(4): 56-62. (In Chinese)

[17] Mohan K, Suresh J A, Ramu P, et al. Microstructure and mechanical behavior of Al7075-T6 subjected to shallow cryogenic treatment. Journal of Materials Engineering and Performance, 2016, 25(6): 2185-2194.

[18] Zhang Z J, Si N C, Sun S C, et al. Thermal fatigue crack growth of ZAISi7Cu4 under different technological conditions. The Chinese Journal of Nonferrous Metals, 2012, 22(11): 3038-3045. (In Chinese)

[19] Liu G L, Si N C, Sun S C, et al. Thermal fatigue crack initiation and propagation of multielement AISi7.5Cu4 alloy. Acta Metallurgica Sinica, 2013, 49(3): 303-310. (In Chinese)

[20] Dumont D, Deschamps A, Brechet Y. A model for predicting fracture mode and toughness in 7000 series aluminium alloys. Acta Materiala, 2004, 52(9): 2529-2540. 